\title{
Mechanical and falling weight impact properties of unidirectional phormium fibre/epoxy laminates
}

\author{
C. Santulli ${ }^{*}$, G. Jeronimidis ${ }^{2}$, I. M. De Rosa ${ }^{3}$, F. Sarasini ${ }^{3}$ \\ ${ }^{1}$ Electrical Engineering Department, Università di Roma - La Sapienza, Via Eudossiana 1800184 Roma, Italy \\ ${ }^{2}$ Centre for Biomimetics, School of Construction Management and Engineering University of Reading, Whiteknights, \\ RG6 6AY, United Kingdom \\ ${ }^{3}$ Research Center for Nanotechnologies applied to Engineering (CNIS) Università di Roma - La Sapienza, \\ Via Eudossiana 18, 00184 Roma, Italy
}

Received 25 June 2009; accepted in revised form 10 August 2009

\begin{abstract}
The falling weight impact properties of composites obtained by introducing $16 \mathrm{wt} \%$ of phormium tenax fibres extracted with two different methods i.e., either manually or by paddocking and scutching and in both cases chemically treated with a $1 \%$ solution of sodium hydroxide, have been investigated. The effect of the two extraction methods on fibre characteristics is compared by the tensile properties of the fibres and the flexural properties, fracture modes and hysteresis cycles parameters (impact energy partition, linear stiffness and normalised penetration energy) of final laminates.

Laminates obtained using paddocked and scutched fibres are clearly superior to those manufactured using the manually extracted fibres: this is due to the more effective fibre impregnation in the former case than in the latter, which results in an improved dissipation of energy during the damping phase of the impact event. It is noteworthy, however, that the low volume of fibres introduced in the laminate with the manufacturing method adopted does not allow obtaining properties comparable with other semi-structural plant fibre composites, such as e.g., hemp fibre reinforced laminates.
\end{abstract}

Keywords: polymer composites, fibre extraction, phormium, falling weight impact testing, hysteresis curves

\section{Introduction}

Natural fibre composites represent a possible route for obtaining more carbon-dioxide neutral materials [1]. The fibres most frequently used in composites aimed at semi-structural applications are mainly bast extracted ones, such as jute, flax and hemp, and a few extracted from other parts of the plant, such as from the fruit skin e.g., coir, or from the leaf e.g., sisal, abaca or pineapple, although studies on a much larger number of natural fibres in composites are present in literature [2]. Concentrating on the leaf fibres, while on one side these appear to be promising for obtaining long stretches of aligned fibres, on the other side they are formed by bundles of many fibre cells, only a small portion of which contribute effectively to fibre-matrix adhesion [3].

In recent years, a renewed interest has been shown for the fibres extracted from the leaves of the phormium tenax, also known as New Zealand flax, which have a traditional use by the Maori people as fibre for weaving mats and ropes [4]. Phormium leaves grow grouped in fans with the youngest leaf in the centre of the fan and older leaves on the outside: the latter reach considerable length, of up to 3 meters, and average width in the order of 100 $150 \mathrm{~mm}$ [5]. Extracted fibres contain around 45\% cellulose, $30 \%$ hemicellulose, $10 \%$ lignin, $10 \%$ 
moisture, and little pectin and wax, although their composition is quite variable depending on the cultivar [6].

Some recent work on the application of alkalitreated phormium fibres arranged in mats used as a reinforcement for epoxy composites showed some promising results, as far as flexural properties are concerned. Electron microscopy highlighted the infrequent presence of kink bands in the individual fibre cells and suggested that wrinkled cell-wall surfaces were able to improve the adhesion at fibrematrix interface [5]. This outcome would in principle suggest a possible use of phormium fibres as a reinforcement for composites. However, a number of issues are still to be addressed: in particular, their impact damage resistance needs to be measured.

In recent years, falling weight impact tests have been performed also on plant fibre composites: a recent study provided some data in this respect [7]. For example, average impact penetration energy of jute $(30 \mathrm{vol} \%) /$ polyester and of sisal (30 vol\%)/ polyester composites is equal to $10.6 \mathrm{~kJ} / \mathrm{m}^{2}$ and $12.2 \mathrm{~kJ} / \mathrm{m}^{2}$ respectively: this is obviously very far from what obtained with fibreglass, where for a similar volume of oriented reinforcement, impact penetration energy usually approaches $100 \mathrm{~kJ} / \mathrm{m}^{2}$ [7].

In addition, some other studies on plant fibre composites highlighted the relation between hysteresis cycles and the mode of failure of these materials under impact loading. This has been obtained by measuring a number of variables from the hysteresis cycle, such as linear stiffness, peak load, extent of first load drop, and partition of impact energy in three terms, namely elastic energy, plastic energy and damping (or rebound) energy [8-10].

In this work, the analysis of hysteresis cycles is applied to the comparison of impact properties of unidirectional phormium fibre/epoxy composites obtained with fibres either extracted manually from the leaves, or retted (i.e., paddocked and scutched). The idea is measuring the effect of the process of retting with respect to manual extraction of fibres, in particular considering that the former is more time consuming and possibly more expensive than the latter. The composite has been laminated in different thickness, keeping constant the volume of reinforcement introduced, at $16 \pm 1 \mathrm{wt} \%$ throughout.

\section{Materials and methods}

\subsection{Fibres extraction}

Phormium leaves show an obvious and quite precise alignment of technical fibres, kept together by a limited amount of resin and non fibrous matter, as from Figure 1.

The fibres were extracted with two different methods:

- In the first case (manual extraction), the leaves were cut to a length of $350 \mathrm{~mm}$ and left to open up to partly separate hemicellulose and non structural matter and separate the aligned bundles of fibres, in a solution of $1 \%$ sodium hydroxide in water. After 24 hours, the fibres are dried from the water in excess, then combed away and separated, so to obtain the technical fibres ready for being impregnated with the polymer resin.

- In the second case (paddocking and scutching), the leaves, as obtained from the plant, hence with length of 2-2.5 m, after removing the curled tips, are washed and fibres are scraped away, trying to preserve straight sections as long as possible. The fibres are then paddocked and scutched. Paddocking involved exposure of the fibres to sun and rain over a few weeks, which again allows separating any non-fibrous matter, which was then removed by scutching. After drying, the fibres were cut at a length of $350 \mathrm{~mm}$ to be treated in a solution of $1 \%$ sodium hydroxide in water for 24 hours, then dried to be inserted in the mould.

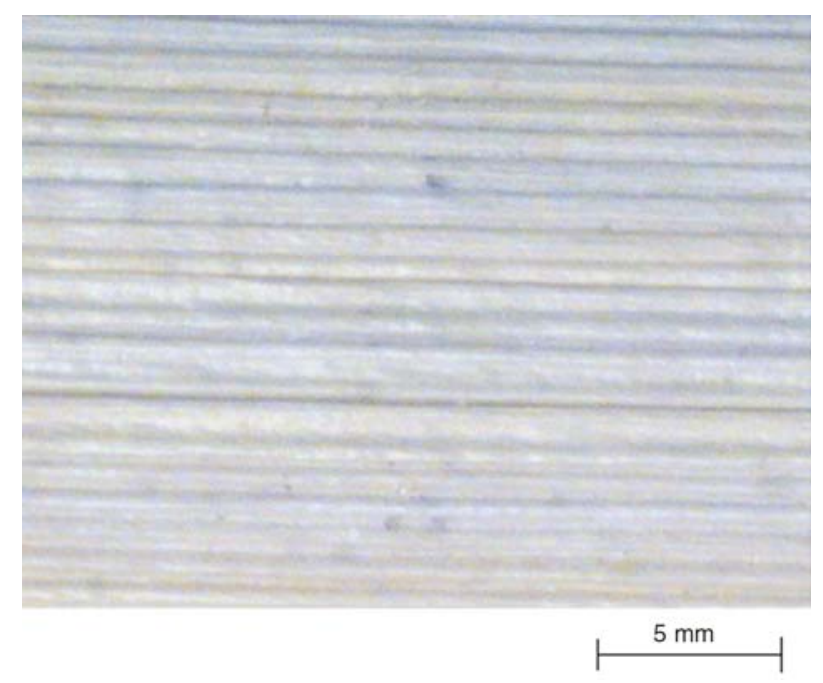

Figure 1. Optical micrograph of a portion of phormium leaf showing aligned fibres 
Table 1. Series of samples tested (IFW = Impact by falling weight)

\begin{tabular}{|c|l|l|c|}
\hline Series & \multicolumn{1}{|c|}{ Fibre extracted } & \multicolumn{1}{c|}{ Type of test } & Thickness [mm] \\
\hline 1 & Manually & Flexural and impact (IFW) & 3.5 \\
\hline 2 & Manually & Impact (IFW) & 7.0 \\
\hline 3 & Paddocked and scutched & Flexural & 3.5 \\
\hline 4 & Paddocked and scutched & Impact (IFW) & 7.0 \\
\hline 5 & Paddocked and scutched & Impact (IFW) & 10.0 \\
\hline
\end{tabular}

In general, the difference between the two methods is that in the first case, manual extraction may be less damaging for the fibres, also because the exposure to the environment is limited, although it may yield technical fibres of variable diameter. In contrast, in the second case paddocking and scutching is a more severe treatment, which involves fibre separation from the leaves before those which on the other side allow the fibres to be 'cleaner' from non-fibrous matter, and hence possibly the values of fibre diameters would be less scattered.

\subsection{Composites manufacturing}

The resin used for composites manufacturing was an Ampreg26 epoxy (by SP systems Plc, Isle of Wight, UK), with Ampreg 26 Slow hardener. Lamination was carried out at $20-22^{\circ} \mathrm{C}$ with 12 hours pressure application and 48 hours post-curing.

Phormium fibre-epoxy laminates were obtained by hand lay-up in a closed matching mould, with planar dimensions $300 \times 150 \mathrm{~mm}$, which allows obtaining a laminate thickness variable from 2 to $10 \mathrm{~mm}$. After cutting, five samples with planar dimensions $250 \times 25 \mathrm{~mm}$ were obtained, with different thickness according to the category of samples. All the categories of samples tested are listed in Table 1.

\subsection{Fibres tensile testing}

The fibres were tested in a universal testing machine model H5KS by Hounsfield Test Equipment Ltd. (Salfords, Redhill, Surrey, UK) equipped with a $1000 \mathrm{~N}$ load cell. The fibres were cut to a gauge length of $80 \mathrm{~mm}$, in a way to avoid as much as possible twisting of the microfibres and presence of split ends, and their ends were bonded by cyanoacrylate adhesive on aluminium circular tabs. The tests were carried out in displacement control using a cross-head speed equal to $2 \mathrm{~mm} / \mathrm{min}$.

\subsection{Composite flexural testing}

Flexural tests have been performed in accordance with ASTM D-790 standard on a 4302 testing machine by INSTRON (High Wycombe, Bucks., UK), using a $10 \mathrm{kN}$ load cell, supporting the specimens in a three-point bending rig with $10 \mathrm{~mm}$ cylindrical supports and a $200 \mathrm{~mm}$ span. Loading was carried out in displacement control at a crosshead speed of $1 \mathrm{~mm} / \mathrm{min}$.

\subsection{Falling weight impact characterization}

Using the same bending rig, falling weight impact tests were carried out. A $12.7 \mathrm{~mm}$ impacting head was employed, with a total (cross-head + impactor) $2.5 \mathrm{~kg}$ mass. The impact energy was varied by changing the falling height of the mass in an IFW5 impact tower by Rosand (Zwick-Roell, Leominster, Herefordshire, UK). During impact testing, force, time and displacement data were acquired. Impact damage patterns have been characterised under an optical stereo- microscope by Carl Zeiss UK (Welwyn Gardens, Herts., UK) with magnification up to 60×. A scanning electron microscope (SEM) S-2500 by Hitachi Europe (Krefeld - Germany) was also used.

\section{Results and discussion}

An optimal fibre extraction results in a compromise between the need of obtaining 'clean' fibres, by a complete removal of wax, pectins, etc., and the requirement of not introducing further damage in the technical fibre, apart from the inherent weaker zones, due to the hierarchised structure of the fibre, often referred to as kink bands [11]. As a result, the analysis of the results would principally try to evaluate the level of improvement, both in quasi-static and dynamic properties of the composite laminates, which can be achieved by a longer but sounder extraction process of fibres, which obviously results in higher costs. 


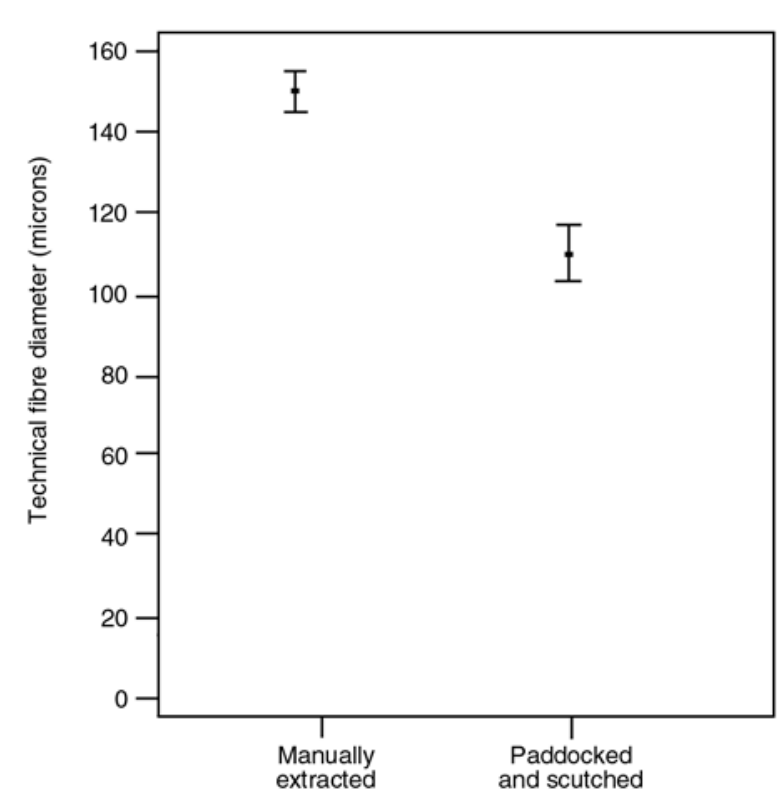

Figure 2. Diameter of technical phormium fibres with the different extraction methods

Measurement by optical microscopy of fibre diameters, as from the results in Figure 2, would indicate that the amount of non-structural matter which is additionally removed by paddocking and scutching would possibly exceed $20 \%$ of total weight. The consequent improvement therefore in tensile properties of the fibres with respect to the manually extracted fibres can be suggested to be at least on the same level. In contrast, the results found in practice suggest that, while thorough removal of non-structural results in a very large improvement of fibre tensile strength, which almost double its average value, albeit retaining a very large scattering, fibre stiffness is not substantially improved by paddocking and scutching (Table 2). It can be suggested that the significant variability in the properties of phormium fibres, even obtained from the same cultivar and from leaves selected by hand, as a result of the variable presence of defects and kink bands, as reported in [11], would lead to this increase in average fibre strength. This is to be verified, especially considering that scattering is large for both the extraction methods considered. The higher tensile modulus values would appear more consistent, though, and be due to the significantly

Table 2. Tensile properties of phormium fibres extracted with the two procedures

\begin{tabular}{|c|c|c|}
\hline $\begin{array}{c}\text { Fibre tensile } \\
\text { properties }\end{array}$ & $\begin{array}{c}\text { Manually } \\
\text { extracted }\end{array}$ & $\begin{array}{c}\text { Paddocked } \\
\text { and scutched }\end{array}$ \\
\hline$\sigma[\mathrm{MPa}]$ & $147 \pm 30$ & $282 \pm 56$ \\
\hline$E[\mathrm{GPa}]$ & $11.5 \pm 3.5$ & $10.4 \pm 2.8$ \\
\hline
\end{tabular}

higher content in structural matter in the technical fibres, which led to some stiffening effect during loading.

When inserting these fibres into the polymer resin, increasing the thickness of the samples would result in the possibility of improved 'locking-up' between unidirectional long fibres, when applying the pressure at mould closure. This is due to their tendency to microbuckling, as it happens when kink bands are present [12], as it is the case with plant fibres. Also, the manufacturing procedure not including thorough degassing adopted would mean that a higher thickness would possibly result also in the higher presence of microvoids: in addition, the control over fibre directionality would be even more difficult. All the above considerations act as limiting factors on the main concept of increasing laminate thickness in order to get sufficient impact resistance.

The results show that extraction scutching and paddocking markedly increases flexural strength and modulus, while it does not result in a significant improvement of flexural work of fracture, as measured from the area below the bending force vs. deflection curve (Table 3 ). In practice, it appears that the possibilities of the fibres in terms of deformation are exploited to the fullest when extracting them manually, whilst loading appears to be more effective after paddocking and scutching resulting in a much larger ultimate stress.

An explanation for this behaviour can come from the comparison of the modes of fracture under impact loading, shown in Figures 3 and 4. The former highlights that the not fully effective impregnation of manually extracted fibres results in a marked influence of internal defects, such as incorrect fibre orientation, whilst the latter depicts, through the complex pattern of flexural impact damage, the presence of hindrances that limit crack propagation, which may result in the higher stiffness of the laminate. Paddocking and scutching led also to fibres which were more easily impregnated by the polymer resin: an example of flexural frac-

Table 3. Flexural properties of phormium fibre composites

\begin{tabular}{|c|c|c|}
\hline $\begin{array}{c}\text { Fibre tensile } \\
\text { properties }\end{array}$ & $\begin{array}{c}\text { Manually } \\
\text { extracted }\end{array}$ & $\begin{array}{c}\text { Paddocked } \\
\text { and scutched }\end{array}$ \\
\hline$\sigma[\mathrm{MPa}]$ & $43 \pm 2.5$ & $60.5 \pm 4.0$ \\
\hline$E[\mathrm{GPa}]$ & $0.8 \pm 0.25$ & $4.4 \pm 0.2$ \\
\hline$W_{\text {flex }}[\mathrm{kJ}]$ & $2.77 \pm 0.6$ & $2.67 \pm 0.47$ \\
\hline
\end{tabular}




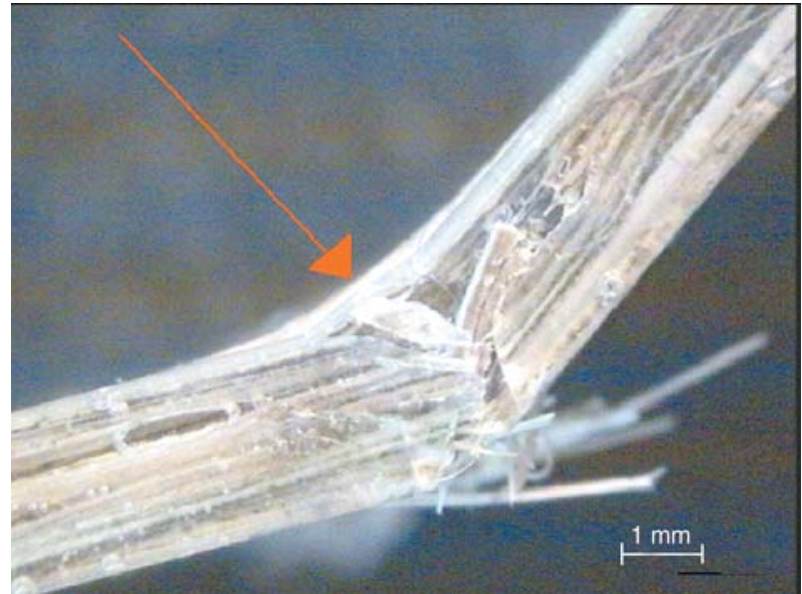

Figure 3. Mode of fracture under impact loading for phormium/epoxy laminates reinforced with manually extracted fibres (centre of the impacted region marked with the red arrow)

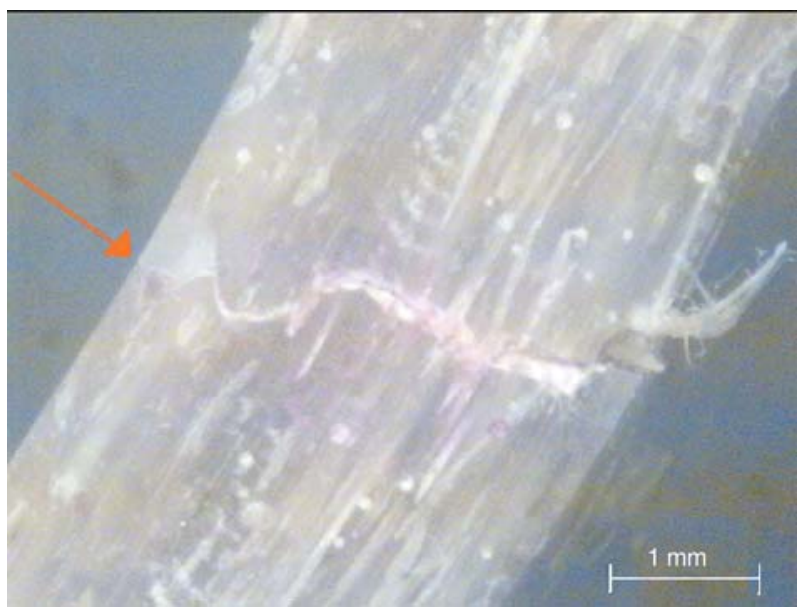

Figure 4. Mode of fracture under impact loading for phormium/epoxy laminates reinforced with paddocked and scutched fibres (centre of the impacted region marked with the red arrow)

ture surface, showing fibres effectively embedded in resin with little pull-out is presented in Figure 5. Both these evidences are confirmed by the study of impact hysteresis cycles, some typical examples of which are reported in Figures $6 \mathrm{a}$ and $6 \mathrm{~b}$ for manually extracted and paddocked and scutched fibres respectively.

The detailed analysis of the data obtained from hysteresis impact cycles show that laminates obtained using paddocked and scutched fibres have globally superior impact properties with respect to the ones manufactured using manually extracted ones. The difference is particularly significant when dealing with linear stiffness, measured by the slope of the elastic part of the curve in $\mathrm{N} / \mathrm{mm}$, normalised against the thickness in $\mathrm{mm}$. More moderate incre-

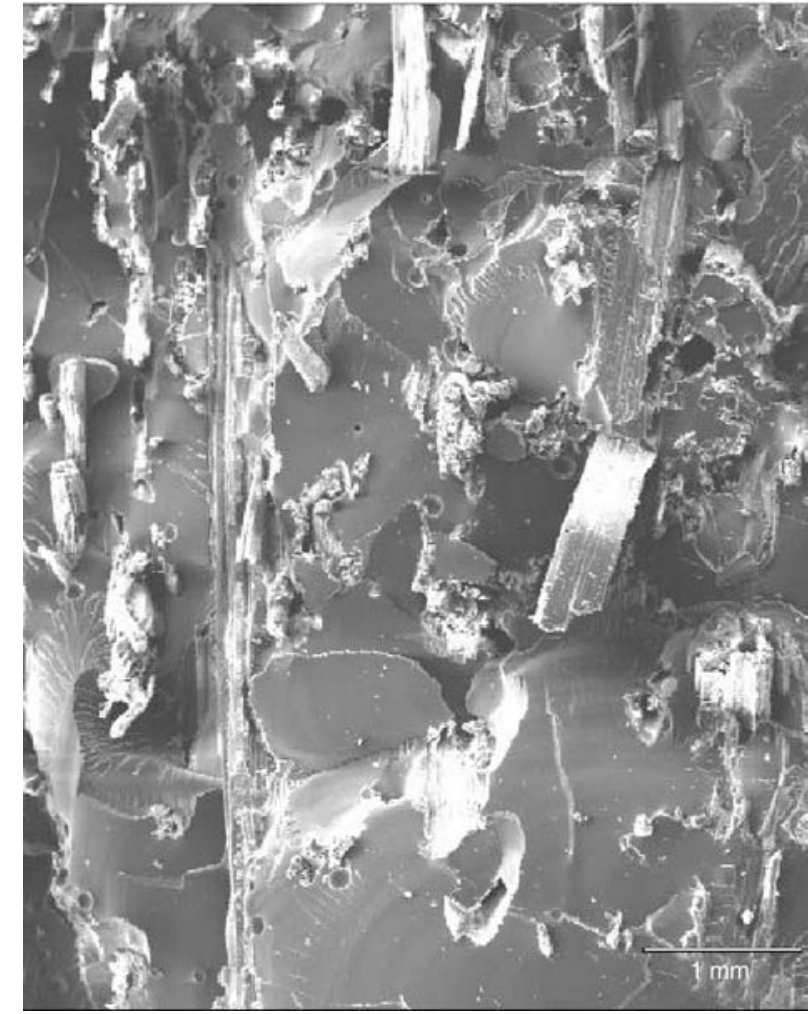

Figure 5. SEM micrograph of composites fracture surface (paddocked and scutched fibres)
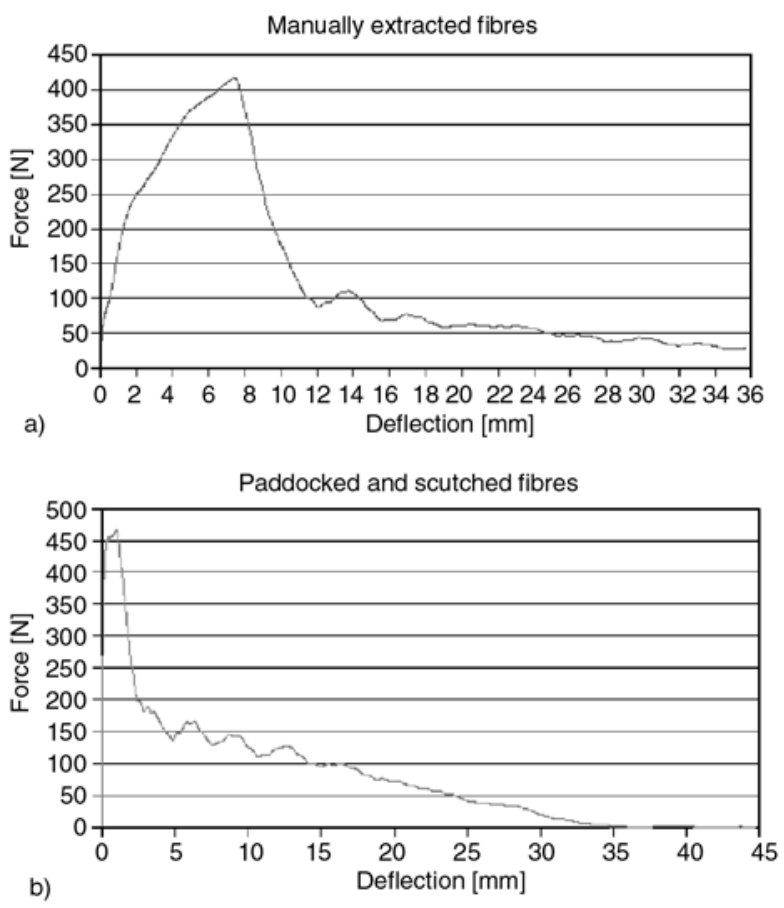

Figure 6. Typical impact hysteresis cycles for two phormium/epoxy laminates $(7 \mathrm{~mm})$ impacted at 3.75 Joules and with fibres extracted in different ways

ments are also shown from normalised maximum load and deflection. The scattering measured on this value is mainly to be related with the non opti- 
Table 4. Values of variables from impact hysteresis cycles for different laminates (all thickness-sensitive values are normalised)

\begin{tabular}{|l|c|c|}
\hline \multicolumn{1}{|c|}{ Properties } & Manually extracted & Paddocked and scutched \\
\hline Max. load/thickness [N/mm] & $57.0 \pm 7.3$ & $102.4 \pm 31.1$ \\
\hline Max. deflection/thickness (pure number) & $4.2 \pm 1.9$ & $6.9 \pm 1.1$ \\
\hline Normalised linear stiffness [N/(mm/mm)] & $313.2 \pm 93.5$ & $2002.3 \pm 553.0$ \\
\hline Damping ratio & $1.7 \pm 0.9$ & $4.6 \pm 2.1$ \\
\hline Penetration energy $\left[\mathrm{kJ} / \mathrm{m}^{2}\right]$ & $1.7 \pm 0.5$ & $3.1 \pm 0.6$ \\
\hline
\end{tabular}

Table 5. Comparative values of normalised linear stiffness $\left[\mathrm{N} /(\mathrm{mm} / \mathrm{mm}]\right.$ and penetration energy $\left[\mathrm{kJ} / \mathrm{m}^{2}\right]$ for different plant fibre reinforced laminates

\begin{tabular}{|l|c|c|}
\hline \multicolumn{1}{|c|}{ Laminate } & $\begin{array}{c}\text { Avg. normalised linear } \\
\text { stiffness [N/(mm/mm)] }\end{array}$ & $\begin{array}{c}\text { Avg. penetration energy } \\
{\left[\mathbf{k J} / \mathbf{m}^{\mathbf{2}}\right]}\end{array}$ \\
\hline Phormium/epoxy (manually extracted fibres) & 313 & 1.7 \\
\hline Phormium/epoxy (paddocked and scutched fibres) & 2002 & 3.1 \\
\hline Jute/polyester [16] & 1462 & 27.0 \\
\hline Hemp/epoxy (unidirectional loose fibres) [14] & 1023 & 16 \\
\hline Hemp/epoxy (cross-ply loose fibres) [14] & 2279 & 70.0 \\
\hline Hemp/epoxy (non-woven mat fibres) [14] & 1984 & 72.0 \\
\hline Flax/epoxy (0.2 mm. thread) [9] & 1134 & 77.5 \\
\hline Flax/epoxy (0.9 mm. thread) [9] & 1628 & 53.3 \\
\hline Flax/epoxy (2.3 mm. thread) [9] & 1155 & 53 \\
\hline
\end{tabular}

mal alignment of fibres and also to the limited total volume of reinforcement, which results in the presence of resin-rich areas (Table 4). In any case, the average value of normalised linear stiffness obtained when using paddocked and scutched fibres is comparable with values measured already on other laminates, although reinforced with a much larger volume of fibres, as reported in Table 5.

Damping ratio has been defined, along the lines of what done already in [13-15], as the ratio between the non-elastic energy $(\mathrm{A} 2+\mathrm{A} 3)$ and the hysteresis energy before damping (or rebound) $(\mathrm{A} 1+\mathrm{A} 2)$ : an example of this measurement is reported for example in Figure 7 for paddocked and scutched fibres laminates. Paddocking and scutching phormium fibres results in the production of laminates which are able to dissipate much more energy (actually, more that twice as much) in the damping phase of the impact event. This very high value of damping ratio appears to be an interesting characteristic of phormium fibres, whenever their diameter is not very scattered, as a result of effective extraction, and in any case much higher than the values measured in [15] on jute, flax and abaca. It is noteworthy, however, that, whatever the fibre extraction method adopted, laminate penetration energy remains quite low, and by no means comparable with other plant fibre reinforced laminates, it is in

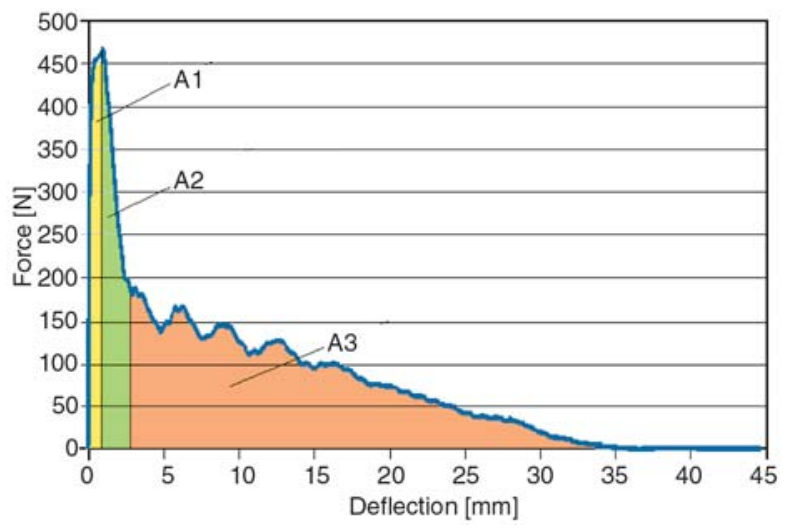

Figure 7. Example of measurement of damping ratio from impact hysteresis curves as $(\mathrm{A} 2+\mathrm{A} 3) /(\mathrm{A} 1+\mathrm{A} 2)$

this respect that the detrimental effect of the low fibre volume introduced is particularly evident (Table 5). It is suggested that phormium fibres may have some interest as reinforcement in impactresistant composites only in much larger volumes and possibly different configurations, in laminates with thickness exceeding few $\mathrm{mm}$ (possibly above $10 \mathrm{~mm}$ or so) or in hybrids including also layers of fibreglass.

In general, the results indicate the importance of the extraction method adopted on the falling weight impact properties of the phormium fibre laminate obtained, especially as regards its damping behaviour during the impact event. This is particularly important in phormium fibres, because of the possibility with effective extraction to reduce the inher- 
ently large variability of cross-sectional shapes and dimensions of technical fibres. This is a feature which has been frequently observed in leafextracted plant fibres e.g., in henequen [17].

\section{Conclusions}

Extraction of phormium fibres by decortication (paddocking and scutching), rather than manual extraction from leaves, results in considerably improved flexural properties of the obtained composites. In addition, the amount of energy absorbed during the damping phase of the falling weight impact event is also much larger, suggesting to be result of the improved fibre-matrix interface.

The main limitation of these composites is in the low amount of fibres that can be introduced in the matrix, because of geometrical limitations, in that the scattering in diameters and shapes between the single fibres, albeit reduced by decortication, is still considerably high. This affects particularly impact penetration energies of the resulting laminates, and could possibly be solved by the use of phormium fibres disposed in non-woven mats or fabrics, which are currently under development.

\section{References}

[1] Saheb D. N., Jog J. P.: Natural fiber polymer composites: A review. Advances in Polymer Technology, 18, 351-363 (1999).

DOI: 10.1002/(SICI)1098-2329(199924)18:4<351:: AID-ADV6>3.0.CO;2-X

[2] Santulli C.: A biomimetic approach to the production of sustainable structural composites using plant fibres. in 'Biologically inspired textiles' (eds.: Ellison M. S., Abbott A. G.) Woodhead Publishing, Cambridge, 95114 (2008).

[3] Mishra S., Mohanty A. K., Drzal L. T., Misra M., Hinrichsen G.: A review on pineapple leaf fibers, sisal fibers and their biocomposites. Macromolecular Materials and Engineering, 289, 955-974 (2004).

DOI: $10.1002 /$ mame. 200400132

[4] Cruthers N. M., Carr D. J., Laing R. M., Niven B. E.: Structural differences among fibers from six cultivars of harakeke (Phormium tenax, New Zealand flax). Textile Research Journal, 76, 601-606 (2006). DOI: $10.1177 / 0040517506065603$

[5] Le Guen M., Newman R.: Pulped Phormium tenax leaf fibres as reinforcement for epoxy composites. Composites Part A: Applied Science and Manufacturing, 38, 2109-2115 (2007).

DOI: 10.1016/j.compositesa.2007.07.001
[6] Lewin M.: Handbook of fiber chemistry. Taylor and Francis, London (2006).

[7] Rodríguez E., Petrucci R., Puglia D., Kenny J. M., Vázquez A.: Characterization of composites based on natural and glass fibers obtained by vacuum infusion. Journal of Composite Materials, 39, 265-282 (2005). DOI: $\underline{10.1177 / 0021998305046450}$

[8] Santulli C., Janssen M., Jeronimidis G.: Partial replacement of E-glass fibres with flax fibres in composites and effect on falling weight impact performance. Journal of Materials Science, 40, 3581-3585 (2005).

DOI: $10.1007 / \mathrm{s} 10853-005-2882-y$

[9] Santulli C.: Falling weight impact damage characterisation on flax/epoxy laminates. International Journal of Materials and Product Technology, 36, 221-228 (2009). DOI: $10.1504 /$ IJMPT.2009.027833

[10] Santulli C., Caruso A. P.: A comparative study on falling weight impact properties of jute/epoxy and hemp/epoxy laminates. Malaysian Polymer Journal, 4, 19-29 (2009).

[11] Newman R., Clauss E., Carpenter J., Thumm A.: Epoxy composites reinforced with deacetylated phormium tenax leaf fibres. Composites Part A: Applied Science and Manufacturing, 38, 2164-2170 (2007). DOI: $10.1016 /$ j.compositesa.2007.06.007

[12] Sutcliffe M. P. F., Fleck N. A.: Microbuckle propagation in fibre composites. Acta Materialia, 45, 921-932 (1997). DOI: 10.1016/1359-6454(95)00410-6

[13] Karger-Kocsis J., Benevolenski O. I., Moskala E. J.: Towards understanding the stress oscillation phenomenon in polymers due to tensile impact loading. Journal of Materials Science, 36, 3365-3371 (2001). DOI: $10.1023 / \mathrm{A}: 1017935323058$

[14] Santulli C., Caruso A. P.: Effect of fibre architecture on the falling weight impact properties of hemp/epoxy composites. Journal of Biobased Materials and Bioproducts, (in press) (2009).

[15] Bledzki A. K., Mamun A. A., Faruk O.: Abaca fibre reinforced PP composites and comparison with jute and flax fibre PP composites. Express Polymer Letters, 1, 755-762 (2007).

DOI: 10.3144/expresspolymlett.2007.104

[16] Santulli C.: Mechanical and impact properties of untreated jute fabric reinforced polyester laminates compared with different E-glass fibre reinforced laminates. Science and Engineering of Composite Materials, 9, 177-188 (2000).

[17] Cazaurang-Martinez M. N., Herrera-Franco P. J., Gonzalez-Chi P. I., Aguilar-Vega M.: Physical and mechanical properties of henequen fibers. Journal of Applied Polymer Science, 43, 749-756 (1991). DOI: 10.1002/app.1991.070430412 